\title{
VALORES DE REFERÊNCIA DE URÉIA E CREATININA PARA JAVALI (SUS scrofa scrofa, LINNAEUS, 1758) EM CATIVEIRO
}

\author{
Thais Helena Desjardins Bergonso ${ }^{1}$, Simone Biagio Chiacchio ${ }^{1}$, Roberto Calderon \\ Gonçalves ${ }^{1}$, Regina Kiomi Takahira ${ }^{1}$, Danilo Otávio Laurenti Ferreira', \\ Sandra Mara Rotter Curotto ${ }^{1}$, Carla Maria Vela Ulian ${ }^{1}$ \\ 1 Universidade Estadual Paulista - UNESP - Campus de Botucatu - chiacchios@fmvz.unesp.br
}

RESUMO: No Brasil, a criação comercial de javalis (Sus scrofa scrofa) está em crescente expansão. Devido à importância dos valores referenciais para as análises bioquímicas como auxílio diagnóstico de processos patológicos e à limitação de dados na literatura sobre esta espécie, foram colhidas amostras de sangue para a determinação de valores bioquímicos em 160 javalis entre 180 a 300 dias de vida, clinicamente saudáveis e confinados. A faixa de referência para creatinina foi semelhante aos valores de referência para suínos $(1,0-2,7 \mathrm{mg} / \mathrm{dL})$. Houve diferença, entre sexos apenas para a dosagem da uréia, onde os machos apresentaram valores mais altos (14,92 $49,30 \mathrm{mg} / \mathrm{dL})$, embora, semelhantes aos suínos $(10-30 \mathrm{mg} / \mathrm{dL})$. As fêmeas, com valores de 13,03 $44,78 \mathrm{mg} / \mathrm{dL}$, não tiveram significância estatística.

Palavras-chave: bioquímica sérica; função renal; valores de referência

\section{REFERENCE VALUES OF THE UREA AND CREATININE IN WILD BOAR (SUS scrofa scrofa, LINNAEUS, 1758) RAISED IN CAPTIVITY}

\begin{abstract}
In Brazil, the commercial breeding of wild boars (Sus scrofa scrofa) is rapidly expanding. Given the significance of reference values for biochemical analysis for diagnosis of pathological processes and the limitation of data in the literature on this species, Blood samples were collected for determination of biochemical values in 160 wild boars from 180 to 300 days old, clinically healthy farms. The reference range for creatinine was similar to the normal range for swine $(1,0-$ $2,7 \mathrm{mg} / \mathrm{dL}$ ). There were differences between genders, only for the determination of urea, where the males were higher, although similar to pigs $(10-30 \mathrm{mg} / \mathrm{dL})$. The females, with values from 13.03 to $44.78 \mathrm{mg} / \mathrm{dL}$, do not have statistically significant.
\end{abstract}

Key Worde: reference values; renal function; serum biochemistry 


\section{INTRODUÇÃO}

O javali, Sus scrofa scrofa, é um animal rústico, ancestral do porco doméstico e nativo da Ásia, África e Europa, e foi introduzido pelo homem na América há muito tempo. Sua domesticação teve início há aproximadamente 5.000 anos, no período Neolítico. Na América do Sul, estes animais foram soltos no Uruguai e Argentina, onde houve o cruzamento descontrolado com suínos domésticos (Sus scrofa domestica) (Hruby e Dewey, 2002).

O javali assemelha-se anatomicamente ao suíno doméstico e vive em grupos de 20 indivíduos, em média, composto por fêmeas com filhotes e machos jovens. Os machos adultos se unem ao grupo apenas na estação reprodutiva e disputam a fêmea até a morte, o vencedor torna-se responsável pela proteção de até 8 javalinas. A fêmea permanece receptiva apenas três dias do estro (21 dias), que ocorre entre novembro e janeiro nos países tropicais. O período médio de gestação é de 115 dias $(100$ - 140) e nascem de 4 a 8 filhotes, geralmente, durante a primavera (Pinheiro, 2000; Hruby e Dewey, 2002; Short, 2003).

A crescente importância econômica do javali devido ao aumento no consumo de sua carne, por ser classificada como alimento nobre, de sabor exótico, com menor quantidade de gordura e de excelentes preços de mercado, constitui numa boa alternativa para pequenas propriedades rurais.

No Brasil, esta atividade também está em expansão, amparada legalmente e regulamentada para criação de animais exóticos, através das Leis no 5197/67 e no 9605/98 e do Decreto no 3179/99 que as regulamentou, além das portarias de $\mathrm{n}^{\circ}$ $118 n / 97$ e de no 102/98 as quais se referem a criadouros comerciais
(IBAMA, 2005 ${ }^{\text {a. }}$ IBAMA, 2005 ; IBAMA, 2005 ${ }^{\text {; }}$ I IBAMA, 2005 ${ }^{\mathrm{d}}$; IBAMA, $2005^{\mathrm{e}}$ ).

De acordo com Coles (1986), o suíno possui doenças espécie específicas e o Médico Veterinário deve realizar avaliação do estado de saúde, bem como para o monitoramento do desempenho zootécnico dos animais. Isto é possível nos suínos, já que são conhecidos seus parâmetros fisiológicos, o que não ocorre nos javalis.

O exame bioquímico tem a finalidade de avaliar as funções metabólicas desempenhadas pelos órgãos e tecidos auxiliando no diagnóstico, acompanhamento terapêutico e prognóstico (Meyer et al., 1995).

Outro fator importante é a carência de trabalhos científicos na Medicina Veterinária sobre esta espécie animal e por conta disto, recorre-se a achados clínicos e laboratoriais do suíno doméstico, o que acaba por induzir a erros, pois o javali é um animal com características próprias (Leman et al., 1986).

Foi neste sentido que Shender et al. (2002) pesquisaram os valores hematológicos e bioquímicos em relação a infecções causadas por helmintos e ectoparasitas em javalis jovens. No total, foram encontradas dez espécies de parasitas e nenhuma correlação significante entre o parasitismo e os parâmetros bioquímicos e hematológicos.

López-Olvera e colaboradores (2006) desenvolveram um estudo para avaliar os efeitos do tratamento para helmintos com ivermectina em javalis jovens. Os valores hematológicos e bioquímicos foram mensurados para avaliar a condição corpórea e o estado imunológico e nutricional, sendo que justamente estes parâmetros clínicos foram afetados pelo parasitismo. 
Harapin e colaboradores (2003) e Brockus e colaboradores (2005) determinaram os valores hematológicos e bioquímicos de javalis adultos da espécie ferus (Sus scrofa ferus) e em mini porcos ("potbellied") respectivamente, uma vez que estas informações são muito limitadas na literatura.

Este trabalho se propôs a determinar os parâmetros fisiológicos para uréia e creatinina séricas em javalis da espécie scrofa (Sus scrofa scrofa) de ambos os sexos, entre 180 e 300 dias de idade.

\section{MATERIAL E MÉTODOS}

Foram selecionados 160 animais, aleatoriamente, filhos de javalis cariotipados (36 cromossomos), clinicamente sadios e divididos em dois grupos, com 80 machos e 80 fêmeas. Os javalis possuíam entre 180 e 300 dias e o peso variou de 30 a $40 \mathrm{~kg}$. Os animais foram alimentados com ração comercial de crescimento para suínos, além de frutas, verduras e legumes ad libitum.

As amostras de sangue foram colhidas com agulhas $40 \times 10$ acopladas a seringas de $10 \mathrm{ml}$, após tricotomia e limpeza da região com algodão embebido em álcool iodado, através de punção da veia cava cranial, entre $7 \mathrm{~h}$ e $8 \mathrm{~h}$ da manhã antes da primeira alimentação. Os animais foram mantidos em jejum num período de $8 \mathrm{~h}$ antes da coleta (Dunne e Leman, 1975; Leman et al., 1986; Straw, 1999; Feldman et al., 2000; Hanie, 2006). O conteúdo da seringa foi transferido para um frasco estéril até formação do coágulo. O soro foi coletado e estocado em microtubo tipo "eppendorf" e armazenado em freezer a - 20oC para posterior análise no laboratório de Patologia Clínica.

As amostras que apresentaram hemólise e lipemia foram descartadas e substituídas para garantir a acurácia dos resultados.

Determinou-se a creatinina pelo método cinético que consiste em adicionar $0,5 \mathrm{~mL}$ de ácido pícrico e 0,5 $\mathrm{ml}$ de tampão glicina - NaOH á $100 \mu \mathrm{L}$ de amostra, deixando essa solução em banho-maria á $250 \mathrm{C}$ até o momento da leitura da absorbância em espectrofotômetro a $510 \mathrm{~nm}$ (Biggs e Cooper, 1961).

A técnica cinética utilizada para determinação da uréia está baseada, também, na leitura da absorbância do espectrofotômetro a $340 \mathrm{~nm}$ após adição de 0,8 $\mathrm{mL}$ de tampão tris e 0,2 $\mathrm{mL}$ de NADH $(0,32 \mathrm{mmol} / \mathrm{L})$ a $10 \mu \mathrm{L}$ de amostra. As soluções permaneceram em banho-maria á 37oC até o momento da leitura dos resultados (Bergmeyer, 1985).

Os dados obtidos foram analisados estatisticamente pela média, desvio padrão, limites mínimo e máximo, lembrando que cada sexo foi analisado separadamente e assumiu-se a normalidade dos dados. Para a definição da faixa de referência foi aplicado o índice de correção de 95\%.

Os valores referenciais para machos e fêmeas foram analisados pelo Teste - $t$ de Student e pela análise da variância bi-caudal, onde valor de $\mathrm{P}<0,05$ evidencia diferença entre os sexos.

\section{RESULTADOS E DISCUSSÃO}

Os resultados foram comparados aos valores fisiológicos de suínos domésticos e com alguns trabalhos realizados em javalis. Houve certa divergência quanto a comparação dos estudos, provavelmente, pelo uso de metodologias diferentes (Shender et al., 2002; Harapin et al., 2003; Brockus et al., 2005; López-Olvera et al., 2006) e faixas etárias distintas (Shender et al., 2002; Harapin et al., 2003; Brockus et 
Tabela 1 - Intervalo de referência dos valores séricos de uréia e creatinina para javalis.

\begin{tabular}{ccc}
\hline & Uréia $(\mathrm{mg} / \mathrm{dl})$ & Creatinina $(\mathrm{mg} / \mathrm{dl})$ \\
\hline Javali (Bergonso, 2007) & $14,92-49,30^{1}$ & $1,02-2,15^{3}$ \\
\hline
\end{tabular}

${ }^{1}$ machos; ${ }^{2}$ fêmeas; ${ }^{3}$ para ambos o sexos, valor de $\mathrm{P}>0,05$.

Tabela 2 - Comparação entre os valores de referência de uréia e creatinina séricas entre suínos domésticos e javalis de ambos os sexos, descritos na literatura.

\begin{tabular}{llcc}
\hline & & Uréia $(\mathrm{mg} / \mathrm{dl})$ & \multicolumn{1}{c}{ Creatinina $(\mathrm{mg} / \mathrm{dl})$} \\
\hline \multirow{2}{*}{ Javali (Bergonso, 2007) } & Machos & $14,92-49,30$ & $1,02-2,15^{1}$ \\
\cline { 2 - 3 } & Fêmeas & $13,03-44,78$ & $-14-20$ \\
\hline Suíno (Lemann et al., 1986) & & $8,0-24$ & $1,0-2,7$ \\
Suíno (Blood et al., 1989) & $21,4-64,2$ & $1,0-2,7$ \\
Suíno (Kaneko et al., 1997). & $10-30$ & $1,0-2,7$ \\
Suíno (Radostits et al.,2002) & & &
\end{tabular}

para ambos os sexos, valor de $\mathrm{P}>0,05$.

al., 2005; López-Olvera et al., 2006). Contudo, os valores foram suficientemente representativos para a comparação.

Os resultados foram analisados com cautela, pois os valores bioquímicos podem ter sofrido influência do ambiente, estação, dieta, sexo e estresse.

Para os animais deste estudo, pode-se verificar que não houve diferença entre os sexos para as dosagens da creatinina. Para a uréia, o intervalo maior foi determinado para machos, embora constatou-se uma pequena diferença numérica entre machos e fêmeas. Pôde-se verificar também que a faixa de referência da uréia ficou um pouco menor do que se considera fisiológico para suínos domésticos (Tabela 1).

Para os valores da uréia entre machos $(14,92-49,30 \mathrm{mg} / \mathrm{dL})$ e fêmeas $(13,03-44,78 \mathrm{mg} / \mathrm{dL})$, estatisticamente, houve uma pequena diferença, mas a faixa de referência ficou um pouco menor do que se considera fisiológico para suínos domésticos $(21,4-64,2$ $\mathrm{mg} / \mathrm{dL}$ ) sem considerar o sexo (Tabela 2) (Kaneko et al., 1997).

A faixa de referência para a creatinina $(1,02-2,15 \mathrm{mg} / \mathrm{dL})$ está dentro dos parâmetros fisiológicos para suínos $(1,0-2,7 \mathrm{mg} / \mathrm{dL})$, embora a diferença proporcional entre os resultados desta pesquisa e a referência para suínos esteja em torno de $30 \%$ (Tabela 2) (Blood et al., 1989; Kaneko et al.,1997; Radostits et al., 2002).

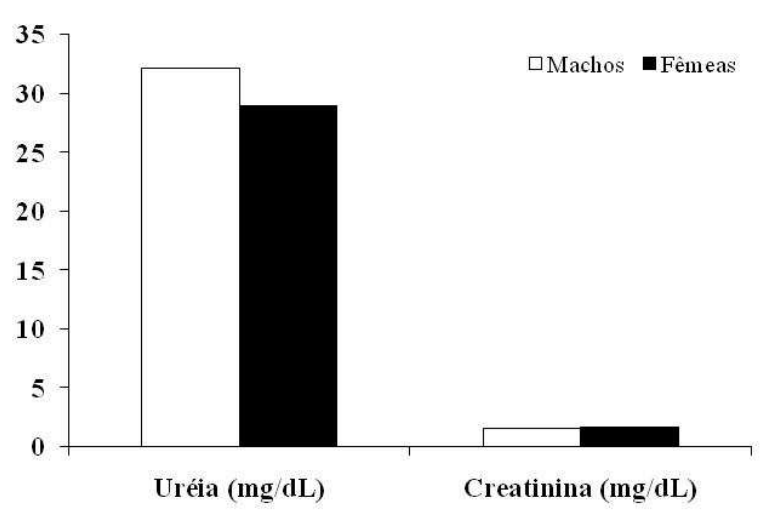

Figura 1 - Comparação das médias de uréia e creatinina em javalis. Diferença estatística entre os sexos para uréia (valor de $\mathrm{P}<0,05$ ).

Constatou-se nos resultados obtidos referentes à uréia que os dados foram significativamente maiores do que os relatados por outros autores os quais realizaram estudos em javalis (Tabela 3 ) (Shender et al., 2002; Harapin et al., 2003; Brockus et al., 2005; LópezOlvera et al., 2006).

Sobre a concentração da creatinina, os dados desta pesquisa foram conflitantes quando comparados com a citação em javalis, pois foram en- 
Valores de referência de uréia e creatinina para javali

Tabela 3 - Comparação de valores séricos de uréia e creatinina obtidos em javalis com a citação de outros autores

\begin{tabular}{llcc}
\hline & & Uréia $(\mathrm{mg} / \mathrm{dl})$ & Creatinina $(\mathrm{mg} / \mathrm{dl})$ \\
\hline \multirow{2}{*}{ Javali (Bergonso, 2007) } & Machos & $14,92-49,30$ & \multirow{2}{*}{$1,02-2,15^{1}$} \\
\cline { 2 - 3 } & Fêmeas & $13,03-44,78$ & \\
\hline Shender et al., 2002 & & $8,4-21,4$ & $0,83-1,17$ \\
Harapin et al., 2003 & $2,03-5,22$ & $2,10-2,92$ \\
Brockus et al., 2005 & $4,2-15,1$ & $1,0-2,3$ \\
López-Olvera et al., 2006 & $4,26-10,75$ & $1,22-1,68$ \\
\hline 'para ambos os sexos; valor de P>0,05. & &
\end{tabular}

contrados tanto valores semelhantes aos animais dos EUA e da Croácia, quanto menores ou mesmo maiores do que os descritos nesse trabalho (Tabela 3). Pode-se atribuir essas diferenças a espécie, idade, alimentação e metodologias utilizadas neste experimento (Shender et al., 2002; Harapin et al., 2003; Brockus et al., 2005; López-Olvera et al., 2006).

Os parâmetros bioquímicos analisados indicam que há diferença entre javalis (Sus scrofa scrofa) e suínos domésticos (Sus scrofa domestica), mesmo em pequeno grau indicando a necessidade de se utilizar referências adequadas a cada espécie animal, evitando-se, assim, erros na interpretação de diagnósticos das enfermidades em geral.

\section{CONCLUSÃO}

Os valores de creatinina em javalis foram semelhantes aos de referência para suínos. Com relação à uréia, houve diferença estatística entre os sexos, sendo que para os machos os dados foram mais elevados, embora semelhantes ao suíno doméstico. Os resultados obtidos por este estudo podem ser utilizados como referência na clínica veterinária ao se tratar de javalis.

\section{REFERÊNCIAS}

BERGMEYER, H.U. Methods of Enzimatic Analisis. 3ed, Florida: VCH Publishers, v.9, p.449-453, 1985.
BIGGS, H.G.; COOPER, J.M. Clinical

Chemistry. Washington: American Association for Clinical Chemistry, v7, n6, p.665-673, 1961.

BLOOD, D.C.; RADOSTITS, O.M. Veterinary Medicine. 7ed. Oxford: The University Press. 1464p., 1989.

BROCKUS, C.W.; MAHAFFEY, E.A.; BUSH, S.E. et al. Hematologic and serum biochemical reference intervals for Vietnamese potbellied pigs (Sus scrofa). Comparative Clinical Pathology, v13, n2, p.162-165, 2005.

COLES, E.H. Veterinary Clinical Pathology. 4ed. Philadelphia: W.B. Saunders, Cap. 5, p.203-216, 1986.

DUNNE, H.W.; LEMAN. AD. (Ed). Diseases of swine. 4ed. Ames: lowa. State University Press, 1212p., 1975.

FELDMAN, B.F.; ZINKL, J.G.; JAIN, N.C. Schalm's Veterinary Hematology. 5ed. Baltimore: Lippincott Willians \& Wilkins. Cap.144, p.949-951, 2000.

HANIE, E.A. Large animal Clinical Procedures for Veterinary Technicians. Saint Louis: Elsevier Mosby.Cap.21, p. 448-449, 2006.

HARAPIN, I.; BEDRICA, L.; HAHN, V.; SOSTARIÉ, B.; GRACNER, D. Haematological and biochemical values in blood of wild boar (Sus scrofa ferus). Veterinarski Arhives, v.73, n6, p.333-343, 2003.

HRUBY, J; DEWEY, T. Sus scrofa - Wild boar. Animal Diversity Web. [2002]. Disponível em:

$<$ http://animaldiversity.ummz.umich.edu/site/acc ounts/information/sus_scrofa.html>. Acesso em: 11/12/2004.

IBAMA - Instituto Brasileiro de Meio Ambiente e Recursos Naturais Renováveis. Lei № 5.197, de 3 de janeiro de 1.967. Disponível em:

<http://www.ibama.gov.br/fauna/legislacao/lei_5 197_67.pdf>. Acesso em: 21/07/2005 .

IBAMA - Instituto Brasileiro de Meio Ambiente e Recursos Naturais Renováveis. Lei no 9.605, de 12 de fevereiro de 1998. Disponível em: 
<http://www.ibama.gov.br/fauna/legislacao/lei_9 605_98.pdf>. Acesso em: 21/07/2005 .

IBAMA - Instituto Brasileiro de Meio Ambiente e Recursos Naturais Renováveis. Decreto no 3.179, de 21 de setembro de 1999 Disponível em:

$<$ http://www.ibama.gov.br/fauna/legislacao/dec 3179_99.pdf>. Acesso em: 21/07/2005 ${ }^{\mathrm{c}}$.

IBAMA - Instituto Brasileiro de Meio Ambiente e Recursos Naturais Renováveis. Portaria no 118n de 15 de outubro de 1997. Disponível em: $<$ http://www.ibama.gov.br/fauna/legislacao/port_ 118_97.pdf>. Acesso em: 21/07/2005 ${ }^{\mathrm{d}}$.

IBAMA - Instituto Brasileiro de Meio Ambiente e Recursos Naturais Renováveis. Portaria no 102/98, de 15 de julho de 1998. Disponível em: $<$ http://www.ibama.gov.br/fauna/legislacao/port 102_98.pdf>. Acesso em: 21/07/2005 ${ }^{\mathrm{e}}$.

KANEKO, J.J.; HARVEY, J.W.; BRUSS, M.L. Clinical Biochemistry of Domestic Animals. 5ed, San Diego: Academic Press, 930p., 1997.

LEMAN, A.D.; STRAW,B.; GLOCK,R.D.G. et al. Diseases of swine. 6ed. Ames: lowa State University Press. Cap.2, p.27-37, 1986.

LÓPEZ-OLVERA, J.; HÖFLE, U.; VICENTE, J. et al.Effects of parasitic helminths and ivermectin treatment on clinical parameters in the European wild boar (Sus scrofa). Parasitology Research, v.98, n6, p.582-587, 2006.
MEYER, D.I.; COLES, E.H.; RICH, L.J.

Medicina de Laboratório Veterinário: Interpretação e Diagnóstico. São Paulo: Roca, p.47-52, 1995.

PINHEIRO, C. Javali - Sus scrofa. [2000]. Disponível em:

<http://www.bragancanet.pt/patrimonio/faunajav ali.htm>. Acesso em: 16/06/2007.

RADOSTITS, O.M.; GAY, C.C. ; BLOOD, D.C. ; HINCHCLIFF, K.W. Clínica Veterinária: Um tratado de doenças de bovinos, ovinos, suínos, caprinos e eqüinos. 9ed. Rio de Janeiro: Guanabara Koogan, p.1648-1649, 2002.

SHENDER, L.A. ; BOTZLER, R.G. ; GEORGE, T.L. Analysis of serum and whole blood values in relation to helminth and ectoparasite infections of feral pigs in Texas. Journal

of Wildlife Diseases, v.38, n.2, p.385-394, 2002.

SHORT, W. Wild boar. (Livestock). Farmers Weekly, v.8474, n. 14, p.2, 2003.

STRAW, B.E. Diseases of swine. 8ed. Ames: lowa State University Press. p.15-16, 1999. 